\title{
The history of cryosurgery in Canada: A tale of two cities
}

Joseph L. Chin, MD ${ }^{1}$; Brian J. Donnelly, MD, $\mathrm{MSc}^{2}$; Shiva M. Nair, MBChB, $\mathrm{PhD}^{1}$; Arnon Lavi, $\mathrm{MD}^{1}$

${ }^{1}$ Urology Division, Department of Surgery, Schulich School of Medicine and Dentistry, Western University, London, ON, Canada; ${ }^{2}$ Department of Surgery, University of Calgary, Calgary Regional Health Authority, Calgary, AB, Canada

Acknowledgment: The authors extend a special thanks to Dr. Juanita Crook for her insightful comments.

Cite as: Can Urol Assoc J 2020 June 16; Epub ahead of print. http://dx.doi.org/10.5489/cuaj.6625

Published online June 16, 2020

$* * *$

\section{Abstract}

Although not commonly available in Canada, cryosurgery (cryoablation) for prostate cancer has been practiced in many countries. The field of cryoablation has evolved significantly over the past 30 years. Two prostate cryoablation programs were started in Canada in the early 1990's, in London ON and Calgary AB, focusing respectively on salvage therapy following radiation failure and primary local treatment. This article chronicles the development of the two programs and outlines the scientific and clinical contributions by investigators at the two centers. 


\section{A brief history of time.......in cryosurgery}

Treatment of tumorous growths was first described centuries ago using a mixture of ice and various "medicinal salts". "Cryosurgery", or cryoablation, for the prostate was initially used for benign prostatic hyperplasia and subsequently extended to prostate cancer in the 1960's by Gonder and Soanes, and further explored by Flocks and Megalli in the early 1970 's(1-3). Initially, the prostate had to be exposed via a perineal incision, whereby a large probe as the source of below-freezing temperature (from a liquid nitrogen course) was directly applied to the prostatic surface. Unfortunately, acceptance of cryoablation as a prostate cancer treatment was significantly hindered by the high complication rate, mainly with urethro-rectal and urethra-cutaneous fistulae (1-3). The main technical limitations were the lack of devices to accurately and reliably monitor placement of the cryo-probes and real-time control of the extent of tissue freezing.

\section{Perfect storm for prostate cryoablation}

A serendipitous "perfect storm" occurred in the early 1990's for cryoablation of internal organs. Firstly, transrectal ultrasound of the prostate was popularize by Lee et al to access the prostate with a transrectal probe, improving prostate imaging and biopsy(4). This led to improved prostate imaging for precise cryoprobe placement and for intra-operative monitoring and control of the freezing process, avoiding excessive freezing and damage to vital adjacent structures such as the rectum and bladder trigone. Secondly, endourological techniques for percutaneous renal stone treatment were pioneered by Smith and colleagues, paving the way for transperineal percutaneous access to the prostate with the Seldinger technique and tract dilation for cryoprobe insertion. Percutaneous access helped minimize fistulous complications. Thirdly, improvements in cryogenics and better understanding of cryo-biology helped the transition from liquid nitrogen-based freezing to argon-based technology which applies the Joule-Thompson effect. The later-generation cryo-systems allow more rapid freezing and slower thawing (optimizing the cytocidal effect) and the smaller-caliber cryoprobes or cryo-needles facilitated more accurate placement and treatment targeting $(5,6)$. Onik et al. were first to use real time transrectal ultrasound (TRUS) for precise probe placement, monitoring the ice-ball enlargement during treatment and visual protection of the rectum(7). Other ancillary improvements in technology included thermal sensors strategically placed periprostatically allowing better temperature monitoring, and urethral warming devices to better protect the urethra and minimize sloughing and subsequent strictures $(4,8,9)$. In this article, we chronicle the development of the first two prostate cancer cryoablation programs in Canada, one in Calgary $\mathrm{AB}$, initially focusing on primary therapy for lower staged cancers and one in London ON, focusing on salvage cryoablation for radiorecurrent prostate cancer. We examine the impact of these two programs on prostate cancer patient care in Canada and their contributions to the Urological literature. 


\section{Prostate cryoablation program in London, $\mathrm{ON}$}

Shortly after the initial presentation on primary prostate cancer cryoablation by Onik and Cohen, the prostate cancer cryosurgery program at University of Western Ontario (UWO, now Western University) in London ON was launched. The first patient was a 66-yearold male with localized intermediate risk prostate cancer, and a relative contraindication for pelvic radiotherapy due to inflammatory bowel disease. His body mass index was 45 . Primary cryoablation was felt to be a viable minimally invasive treatment, which was carried out in 1992. A crucial element of the successful program was the partnership with a Radiologist with expertise in prostate ultrasound. Dr. Donal Downey was invaluable in the perioperative management and follow-up assessment of the cryoablation patients including serial TRUS-guided biopsies.

Adding to the aforementioned "perfect storm" was the invention by a medical physicist, Dr. Aaron Fenster at the Robarts Research Institute in London ON, a 3dimensional ultrasound imaging system which was incorporated $(10,11)$ into the intraoperative algorithm for prostate cancer ablation (Fig. 1A). The "almost instantaneous" 3-D reconstruction software permitted intraoperative verification of accurate cryo-probe placement in the transverse, sagittal and the previously unavailable coronal views of the prostate (Fig. 1B, 1C). This modification of transrectal ultrasoundguided prostate cryoablation, published in 1998, was a "world-first" (11). It facilitated real-time confirmation of cryoprobe placement in 3-D and monitoring of the freezing process with views of the expanding ice-balls nearing the rectal wall (Fig. 1C, 1D). The added features should theoretically improve efficacy and reduce the morbidity of prostate cryoablation.

Traditionally, patients who had experienced treatment failure following primary radiotherapy have been reflexively and routinely placed on androgen deprivation therapy (ADT). This wide-spread practice might at times be premature or even inappropriate as a significant proportion of such patients could be candidates for local salvage therapy, i.e. salvage prostatectomy or some form of salvage ablative therapy. To partly fulfill this unmet need, the decision was made at UWO to concentrate on treating patients who had localized histologically proven recurrence following primary radiotherapy.

A major contributor to the salvage cryoablation program at UWO was Dr. Juanita Crook, a Radiation Oncologist in Ottawa and subsequently, in Toronto. Dr. Crook was investigating the time course of histologic response to radiation seen in post-radiotherapy prostate biopsies. Dr. Crook and colleagues incorporated post-radiotherapy biopsies as early as 12 to 18 months into their follow-up algorithm and noted a significant proportion of patients with "early" post-radiotherapy positive biopsies did develop progressive disease. Although some were "indeterminant" and eventually resolved, others persisted and started to drive up the PSA (12-14). Dr. Crook referred numerous patients to the 
UWO program for salvage cryoablation, patients diagnosed with localized persistent prostate cancer following radiotherapy who otherwise might have waited much longer prior to a diagnosis of radio-recurrence, by which time the window of opportunity for cure might have been missed. Radiation oncologists from many other Canadian cancer centers and other urologists following suit with their referrals.

The results on the initial 118 patients with median follow-up of 18.6 months (range 3 to 54) were published in 2001, Kaplan-Meier plots showed patients free of histological recurrence levelling at $87 \%(15)$. Predictors of treatment failure included, as expected, high pre-cryoablation Prostate Specific Antigen (PSA) level $>10 \mathrm{ng} / \mathrm{ml}$, high pre-radiotherapy Gleason score $(\geq 8)$ and high pre-radiotherapy stage $(\geq \mathrm{T} 3)$. These results mirrored those by Drs. Pisters and von Eschenbach et al from M.D..Anderson Cancer Center who reported a 2-year biochemical recurrence free survival of $74 \%$ for precryotherapy PSA $<10 \mathrm{ng} / \mathrm{ml}$ compared to $28 \%$ for PSA $>10 \mathrm{ng} / \mathrm{ml}(16)$.

Serial prostate biopsy was part of the follow-up routine, regardless of biochemical or clinical response. This contributed to the understanding of the natural history of salvage cryoablation, to the patterns of treatment failure, and to improved patient selection (17). UWO was a key member of a consortium of several North American cryosurgery centers which designed a pretreatment nomogram predicting biochemical failure after salvage cryoablation for locally recurrent prostate cancer(18).

With a prospectively maintained database and longer follow-up on a larger cohort 187 patient at UWO, durable responses were noted, with median follow-up of 117 months the BCR free rates at 10 years was $35 \%$ with overall survival rates of $76 \%(17,19,20)$. Further update on the cohort of 187 patients, with median follow up now very mature at 149 months, 12 -year overall survival was $56 \%$, while cancer specific survival (CSS) was reported at 81\% (21). Again, pre-radiation Gleason score and grade, pre-radiation T stage, pre-Cryoablation PSA levels were found to be predictors of CSS. Another parameter, PSA nadir post-cryoablation, was found to be prognostic. Importantly, $49 \%$ of the patients had not required androgen deprivation therapy and for those who did progress onto requiring ADT, there was a clinically meaningful delay of median 101 months from time of cryoablation to commencement of ADT (22). There are ongoing collaborative efforts with other institutions that have comparable large and mature databases (Mayo Clinic, Memorial Sloan Kettering Cancer Centre), on salvage radical prostatectomy. The combined analyses have contributed to the knowledge and guidance for management of radio-recurrent prostate cancer( 23,24$)$. Notably, when compared to patients without further local therapy after radiation recurrence, there has been improvement in CSS and OS associated with salvage local therapy (25). 


\section{Randomized trial on advanced staged prostate cancer at UWO in London, ON: Primary cryoablation vs. external beam radiotherapy}

In addition to the salvage cryoablation program, in mid-2000 a randomized trial on locally advanced prostate cancer, comparing the relative efficacy of primary cryoablation versus primary radiotherapy was conducted at UWO. Patients with cT2C, cT3A and cT3B were randomized to either primary whole gland cryoablation or external beam radiotherapy (standard dose was $66 \mathrm{~Gy}$ ), with both groups receiving 3 months of ADT prior to and 3 months following their prostate intervention.

Shortly after the inception of this trial, however, there was a global major paradigm shift in the radiotherapy management for prostate cancer at high risk for metastasis. Firstly, Bolla et al published preliminary results of an EORTC (European Organization for Research and Treatment of Cancer) randomized trial with external beam radiotherapy and 3 years of adjuvant ADT versus no ADT. The ADT group had significantly better disease-free and overall survival (26-28). Secondly, there had been increasing evidence of therapeutic benefits of dose escalation for patients undergoing external beam radiotherapy compared to the "conventional" dose $(\leq 68 \mathrm{~Gy})(29,30)$. These two developments suggested the radiotherapy arm of the UWO randomized trial provided suboptimal treatment. Accrual to the trial drastically decreased and the trial was stopped with enrolment of only 62 patients out of the original target of 144 (31). Deficiencies in numbers and trial design not with-standing, with long-term follow-up, disease specific survival and overall survival were comparable between the groups. However, the 8-year biochemical disease-free survival rate was significantly lower in the cryoablation group $(17.4 \%$ vs $59.1 \%)(p=0.01)(32)$. Cryoablation may be more suited for less bulky prostate cancer. Longer duration neoadjuvant hormonal therapy or a multimodal approach should improve biochemical disease-free survival in this patient population. This trial was one of the first attempts world-wide in comparing two interventional modalities for prostate cancer in a randomized setting. The other such randomized trial, led by Dr. B. Donnelly, was taking place contemporaneously across the country $3000 \mathrm{~km}$ away in Calgary AB (33).

\section{Primary prostate cryoablation program in Calgary, $A B$}

In 1993, cryoablation as a treatment for localized prostate cancer was presented at a meeting of the G.U committee of R.T.O.G and appeared interesting. Coincidentally, at that time, there was a program in place to treat liver metastases with cryoablation at Tom Baker Hospital, in Calgary. This program was run by Dr John Saliken, an interventional radiologist. We got together with Dr. Saliken with a view to exploring the role of cryoablation in patients with localized prostate cancer. A proposal for a Phase II pilot study was submitted to the Alberta Cancer Board, who agreed to fund a pilot of 30 cases, on condition that there was no surgical fee. 
Patients were invited to participate in a prospective, non-randomized pilot study of the safety and efficacy of cryosurgery in treating localized prostate cancer. Recruitment began in December 1994 and closed in February 1998. All patients had histologically proven adenocarcinoma of the prostate with PSA readings $<30 \mathrm{ng} / \mathrm{mL}$ (Hybritech). All patients had negative bone scans. If the risk of lymph node involvement exceeded 5\% as calculated by the formula of Roach, laparoscopic pelvic lymph node dissection was carried out prior to inclusion in the study(34). It was explained to all patients that radical prostatectomy and XRT are the standard treatment choices and that cryoablation was, at the time, an investigational modality.

The objective of this study was to assess the safety and short-term results of this treatment, with a view to conducting a Phase III randomized trial comparing cryoablation with External Beam Radiation (XRT) in localized prostate cancer. Accrual of the Phase II pilot study went very well, but we were unwilling to begin the Phase III randomized trial until we had 3-year results on at least 30 cases, so the work continued, and eventually 76 patients were treated (with 11 patients receiving a repeat treatment (35-37). A single freeze/thaw cycle was used in the first 10 cases, changing to 2 freeze/thaw cycles from case 11 onwards, which was becoming the standard procedure. The 5 -year overall and cancer-specific survival rates are $89 \%$ (95\% C.I. $83-97 \%)$ and $98.6 \%$ (95\% C.I. 96-100), respectively. The undetectable PSA rate $(\leq 0.3 \mathrm{ng} / \mathrm{mL})$ for low risk patients $(13)$ was $60 \%$ at 5 years, moderate risk (23): $77 \%$; high risk (40): $48 \%$. PSA less than $1.0 \mathrm{ng} / \mathrm{mL}$ at 5 years is $75 \%, 89 \%$ and $76 \%$ respectively(36). At this point, it was felt appropriate to proceed to the Phase III randomized trial.

Alberta Cancer Board agreed to fund the work, (with the same stipulation of no surgical fee) and further funding was obtained from National Cancer Institute of Canada. A multidisciplinary team was set up comprised of Urology, Interventional Radiology, Radiation Oncology, Medical Oncology and Biostatistics. Patient eligibility was similar to the pilot with one significant difference that PSA was $<20 \mathrm{ng} / \mathrm{ml}$ (rather than $<$ $30 \mathrm{ng} / \mathrm{ml}$ ). Clinical bulky T3 cases were not eligible. Accrual to this type of trial was very difficult, so eligible patients and their significant others were invited to small group presentations of all information. The presenters were an Urologist, a Radiation Oncologist and a Medical Oncologist. Out of 627 eligible patients, 244 (38\%) agreed to randomization, which was a very high accrual rate. The study ran from December 1997 to February 2003 and was closed prematurely due to slowing accrual. All patients received neoadjuvant hormones, in both arms, as this was standard radiotherapy practice at the time. All patients who were randomized to the radiotherapy arm were treated with a standard 4-field box technique (2 Gy daily, 5 days per week) using high-energy megavoltage (MV) x-rays of 10MV.The prescribed radiation dose was $68 \mathrm{~Gy}$. The dose was increased to $70 \mathrm{~Gy}$ in early 2000 and finally to $73.5 \mathrm{~Gy}$ in late 2002 in response to 
changing standards of practice. The results at 100 month follow-up essentially showed that both treatments had similar outcomes $(33,38)$. This trial, along with the one on locally advanced disease by Chin et al (31), remain as two of the earliest randomized trials world-wide in prostate cancer comparing different interventional modalities. Dr John Robinson, clinical psychologist with the program, published several notable articles on the quality of life outcomes of the patients who had undergone either primary or salvage cryoablation(38-40). Drs. Rewcastle, Muldrew and Baissolov conducted much laboratory work on the biomechanics of cryoablation, resulting in multiple publications and presentations (41-44). With the significant contributions by the Calgary program in primary cryoablation, Dr. Donnelly was a major contributor on the "Best practice statement on cryosurgery for the treatment of localized prostate cancer" issued by the American Urological Association in 2008 (45).

\section{Salvage cryoablation program in Calgary, $A B$}

A salvage cryoablation phase II trial was also initiated Tom Baker Hospital in Calgary in 1998 to treat radio-recurrent prostate cancer patients. Selection criteria were strict.

Biopsy proven residual cancer in the prostate, negative metastatic work up, PSA doubling time $>1$ year, PSA $<20 \mathrm{ng} / \mathrm{ml}$. Forty-six patients were treated. Using the PSA definitions for biochemical failure as PSA $<0.3 \mathrm{ng} / \mathrm{ml}, 51 \%$ and $44 \%$ were considered disease free at 1 and 2 years, respectively $(39,46)$. There was 1 patient with a recto-prostatic fistula. On the basis of these results, salvage cryoablation was (and still is) offered to suitable patients in Calgary. We have modified our patient eligibility is accordance with the work of Dr. Chin and colleagues showing that the best results are achieved with PSA $<5 \mathrm{ng} / \mathrm{ml}$ in the recurrent patient.

Cryoablation continues to be available in Calgary (and Edmonton), both as a primary, and salvage treatment for suitable patients. In the primary setting, there are many patients who are not suitable for either surgery or radiation, and this provides a good option for such cases. Furthermore, many patients live long distances from a radiotherapy facility (some from outside of Alberta), thus making many weeks of treatment difficult. For these men, cryoablation is a viable option with only an overnight stay, and in some cases, even same-day discharge is an option. The risk of fistula formation was held up as an objection to this treatment, but in the primary cases, this should not be a concern in competent hands. Erectile dysfunction is universal initially with whole-gland ablation, but approximately $30 \%$ of men resume sexual activity, similar to the number following external beam radiotherapy in our prospective trial.

In the salvage setting, as noted earlier from the UWO experience, the vast majority of salvageable men are not offered this local treatment, and instead are only offered androgen deprivation therapy, with the attendant morbidities. As we have shown, a 
substantial proportion of these cases could be potentially salvaged by local ablation therapy, either cryoablation or HIFU, obviating or deferring ADT.

\section{Conclusions}

The two parallel prostate cryosurgery programs in Canada, both started in 1990's, one focusing initially on primary ablation and one concentrating in salvage ablation for radiorecurrent disease, have had a combined output of over 50 peer-reviewed publications. They have made contributions to improved understanding of cryobiology, to technical advances of prostate cryoablation, as well as cryosurgery-related issues of imaging and histopathology. More importantly, clinical information such as patient selection, prognostication, quality of life issues, and the role of cryoablation in the entire spectrum of prostate cancer management have benefited world-wide from the experience and lessons learned via these Canadian two programs. This "tale of two cities" on the history of prostate cryoablation in Canada, unlike the "Tale" by Charles Dickens, appears to have had a favorable outcome.

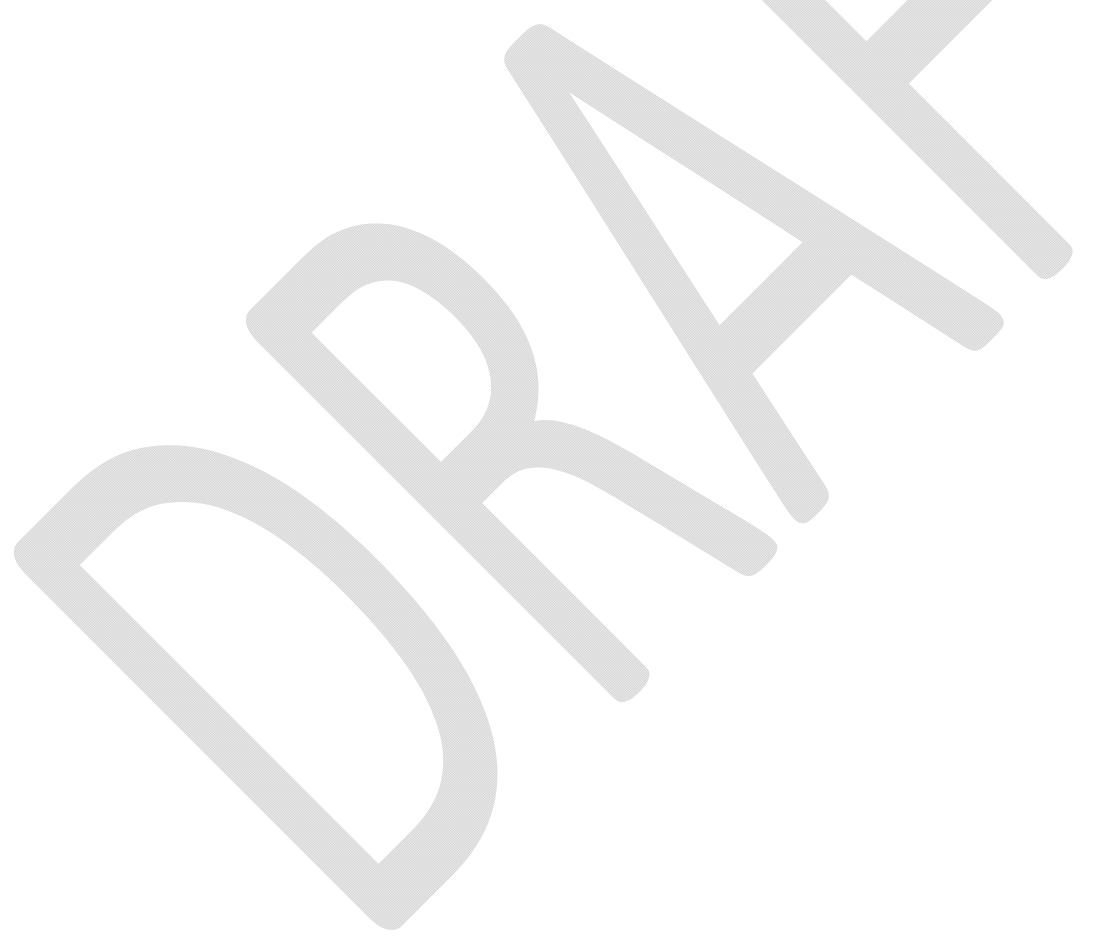




\section{References}

1. Gonder MJ, Soanes WA, Shulman S. Cryosurgical treatment of the prostate. Invest Urol [Internet]. 1966 Jan [cited 2020 Jan 15];3(4):372-8. Available from: http://www.ncbi.nlm.nih.gov/pubmed/4160242

2. Megalli MR, Gursel EO, Veenema RJ. Closed perineal cryosurgery in prostatic cancer. New probe and technique. Urology [Internet]. 1974 Aug [cited 2020 Jan 15];4(2):220-2. Available from: http://www.ncbi.nlm.nih.gov/pubmed/4851058

3. Flocks RH, Nelson CM, Boatman DL. Perineal cryosurgery for prostatic carcinoma. J Urol [Internet]. 1972 Dec [cited 2020 Jan 15];108(6):933-5. Available from: http://www.ncbi.nlm.nih.gov/pubmed/5082750

4. Lee F, Bahn DK, McHugh TA, Onik GM, Lee FT. US-guided percutaneous cryoablation of prostate cancer. Radiology. 1994;192(3):769-76.

5. Rewcastle JC, Sandison GA, Saliken JC, Donnelly BJ, Mckinnon JG. Considerations during clinical operation of two commercially available cryomachines. J Surg Oncol. 1999;71(2):106-11.

6. Han K-R, Cohen JK, Miller RJ, Pantuck AJ, Freitas DG, Cuevas CA, et al. Treatment of organ confined prostate cancer with third generation cryosurgery: preliminary multicenter experience. J Urol [Internet]. 2003 Oct [cited 2020 Jan 20];170(4 Pt 1):1126-30. Available from: http://www.ncbi.nlm.nih.gov/pubmed/14501706

7. Onik GM, Cohen JK, Reyes GD, Rubinsky B, Chang Z, Baust J. Transrectal ultrasound-guided percutaneous radical cryosurgical ablation of the prostate. Cancer. 1993;72(4):1291-9.

8. Cohen JK, Miller RJ. Thermal protection of urethra during cryosurgery of prostate. Cryobiology. 1994;31(3):313-6.

9. Wong WS, Chinn DO, Chinn M, Chinn J, Tom WL, Tom WL. Cryosurgery as a treatment for prostate carcinoma. Results and complications. Cancer. 1997 Mar 1;79(5):963-74.

10. Chin JL, Downey DB, Onik G, Fenster A. Three-dimensional prostate ultrasound and its application to cryosurgery. Tech Urol [Internet]. 1996 [cited 2020 Jan 16];2(4):187-93. Available from: http://www.ncbi.nlm.nih.gov/pubmed/9085539

11. Chin JL, Downey DB, Mulligan M, Fenster A. Three-dimensional transrectal ultrasound guided cryoablation for localized prostate cancer in nonsurgical candidates: a feasibility study and report of early results. J Urol [Internet]. 1998 Mar [cited 2020 Jan 16];159(3):910-4. Available from: http://www.ncbi.nlm.nih.gov/pubmed/9474181

12. Crook J, Malone S, Perry G, Bahadur Y, Robertson S, Abdolell M. Postradiotherapy prostate biopsies: What do they really mean? Results for 498 patients. Int J Radiat Oncol Biol Phys. 2000 Sep;48(2):355-67.

13. Crook JM, Bahadur YA, Robertson SJ, Perry GA, Esche BA. Evaluation of radiation effect, tumor differentiation, and prostate specific antigen staining in sequential prostate biopsies after external beam radiotherapy for patients with prostate carcinoma. Cancer [Internet]. 1997 Jan 1 [cited 2020 Apr 6];79(1):81-9. 
Available from: http://www.ncbi.nlm.nih.gov/pubmed/8988730

14. Crook JM, Bahadur YA, Bociek RG, Perry GA, Robertson SJ, Esche BA. Radiotherapy for localized prostate carcinoma. The correlation of pretreatment prostate specific antigen and nadir prostate specific antigen with outcome as assessed by systematic biopsy and serum prostate specific antigen. Cancer [Internet]. 1997 Jan 15 [cited 2020 Apr 8];79(2):328-36. Available from: http://www.ncbi.nlm.nih.gov/pubmed/9010106

15. Chin JL, Pautler SE, Mouraviev V, Touma N, Moore K, Downey DB. Results of salvage cryoablation of the prostate after radiation: identifying predictors of treatment failure and complications. J Urol [Internet]. 2001 Jun [cited $2020 \mathrm{Feb}$ 20];165(6 Pt 1):1937-41; discussion 1941-2. Available from: http://www.ncbi.nlm.nih.gov/pubmed/11371885

16. Pisters LL, Perrotte P, Scott SM, Greene GF, von Eschenbach AC. Patient selection for salvage cryotherapy for locally recurrent prostate cancer after radiation therapy. J Clin Oncol [Internet]. 1999 Aug [cited 2020 Jan 30];17(8):2514-20. Available from: http://www.ncbi.nlm.nih.gov/pubmed/10561317

17. Ng CK, Touma NJ, Chalasani V, Moussa M, Downey DB, Chin JL. The pattern of prostate cancer local recurrence after radiation and salvage cryoablation. J Can Urol Assoc. 2011;5(6).

18. Spiess PE, Katz AE, Chin JL, Bahn D, Cohen JK, Shinohara K, et al. A pretreatment nomogram predicting biochemical failure after salvage cryotherapy for locally recurrent prostate cancer. BJU Int [Internet]. $2010 \mathrm{Jul}$ [cited $2020 \mathrm{Feb}$ 20];106(2):194-8. Available from: http://www.ncbi.nlm.nih.gov/pubmed/19922545

19. Ng CK, Moussa M, Downey DB, Chin JL. Salvage Cryoablation of the Prostate: Followup and Analysis of Predictive Factors for Outcome. J Urol. 2007 Oct;178(4):1253-7.

20. Williams AK, Martínez CH, Lu C, Ng CK, Pautler SE, Chin JL. Disease-free survival following salvage cryotherapy for biopsy-proven radio-recurrent prostate cancer. Eur Urol [Internet]. 2011 Sep [cited 2019 Oct 28];60(3):405-10. Available from: http://www.ncbi.nlm.nih.gov/pubmed/21185115

21. Siddiqui KM, Billia M, Al-Zahrani A, Williams A, Goodman C, Arifin A, et al. Long-Term Oncologic Outcomes of Salvage Cryoablation for Radio-Recurrent Prostate Cancer. J Urol. 2016 Oct 1;196(4):1105-11.

22. Nair SM, Peters M, Abed H, Van Der Voort Van Zyp J, Van Son M, Chin JL. Tumor control outcomes of salvage cryotherapy for radiorecurrent prostate cancer at median 12 years follow-up. Eur Urol Suppl. 2019 Mar 1;18(1):e869.

23. Nair SM, Lyon T, Dewar M, Rangel L, Abed H, Hetou K, et al. Salvage cryotherapy versus salvage radical prostatectomy for radiorecurrent prostate cancer: Long-term oncologic outcomes. Eur Urol Suppl. 2019 Mar 1;18(1):e872.

24. McPherson VA, Nair SM, Tin AL, Dewar M, Siddiqui K, Sjoberg DD, Vickers A, Eastham J CJ. Comparison of salvage prostatectomy vs. salvage ablative therapy for biopsy-proven radio-recurrent localized prostate cancer. Vol. 13 No. 6S5 
(2019): CUAJ June-SUPPL 5 | Canadian Urological Association Journal [Internet]. 2019 [cited 2020 Apr 8]. Available from: https://cuaj.ca/index.php/journal/issue/view/196

25. Nair S, Warner A, Rodrigues G CJ. MP70-02 DOES SALVAGE WHOLE GLAND CYROABLATION THERAPY CONFER SURVIVAL ADVANTAGE TO PATIENTS WHO FAILED PRIMARY RADIOTHERAPY FOR PROSTATE CANCER? | Journal of Urology [Internet]. 2020 [cited 2020 Apr 8]. Available from: https://www.auajournals.org/doi/abs/10.1097/JU.0000000000000950.02

26. Kouloulias VE, Giraud J-Y, Davis BJ, Dusserre A, Zurlo A, Bolla M. Quality assurance of the 22961 EORTC trial. A phase III study of the optimal combination of hormonal adjuvant treatment by LHRH analogue and radiation therapy for the management of locally advanced prostate cancer: the dummy run. Radiother Oncol [Internet]. 2004 Oct [cited 2020 Apr 6];73(1):11-20. Available from: http://www.ncbi.nlm.nih.gov/pubmed/15465141

27. Bolla M, Descotes JL, Artignan X, Fourneret P. Adjuvant treatment to radiation: Combined hormone therapy and external radiotherapy for locally advanced prostate cancer [Internet]. Vol. 100, BJU International. 2007 [cited 2020 Apr 6]. p. 44-7. Available from: http://www.ncbi.nlm.nih.gov/pubmed/17594359

28. Bolla M, Van Tienhoven G, Warde P, Dubois JB, Mirimanoff RO, Storme G, et al. External irradiation with or without long-term androgen suppression for prostate cancer with high metastatic risk: 10-year results of an EORTC randomised study. Lancet Oncol [Internet]. 2010 Nov [cited 2020 Apr 6];11(11):1066-73. Available from: http://www.ncbi.nlm.nih.gov/pubmed/20933466

29. Peeters STH, Heemsbergen WD, Koper PCM, Van Putten WLJ, Slot A, Dielwart $\mathrm{MFH}$, et al. Dose-response in radiotherapy for localized prostate cancer: Results of the Dutch multicenter randomized phase III trial comparing 68 Gy of radiotherapy with 78 Gy. J Clin Oncol. 2006 May 1;24(13):1990-6.

30. Pollack A, Zagars GK, Starkschall G, Antolak JA, Lee JJ, Huang E, et al. Prostate cancer radiation dose response: Results of the M. D. Anderson phase III randomized trial. Int J Radiat Oncol Biol Phys. 2002 Aug 1;53(5):1097-105.

31. Chin JL, Ng C-K, Touma NJ, Pus NJ, Hardie R, Abdelhady M, et al. Randomized trial comparing cryoablation and external beam radiotherapy for T2C-T3B prostate cancer. Prostate Cancer Prostatic Dis [Internet]. 2008 Mar [cited 2020 Feb 20];11(1):40-5. Available from: http://www.ncbi.nlm.nih.gov/pubmed/17579613

32. Chin JL, Al-Zahrani AA, Autran-Gomez AM, Williams AK, Bauman G. Extended followup oncologic outcome of randomized trial between cryoablation and external beam therapy for locally advanced prostate cancer (T2c-T3b). J Urol [Internet]. 2012 Oct [cited 2020 Feb 20];188(4):1170-5. Available from: http://www.ncbi.nlm.nih.gov/pubmed/22901586

33. Donnelly BJ, Saliken JC, Brasher PMA, Ernst SD, Rewcastle JC, Lau H, et al. A randomized trial of external beam radiotherapy versus cryoablation in patients 
with localized prostate cancer. Cancer. 2010 Jan 15;116(2):323-30.

34. Roach M, Marquez C, Yuo HS, Narayan P, Coleman L, Nseyo UO, et al. Predicting the risk of lymph node involvement using the pre-treatment prostate specific antigen and gleason score in men with clinically localized prostate cancer. Int J Radiat Oncol Biol Phys [Internet]. 1994 Jan 1 [cited 2020 Apr 6];28(1):33-7. Available from: http://www.ncbi.nlm.nih.gov/pubmed/7505775

35. Donnelly BJ, Saliken J, McDougall L, Temple WJ. Pilot study to determine safety and short-term outcome of percutaneous cryoablation in the treatment of localized prostate cancer (stages T1C-T3C NO MO). Can J Urol [Internet]. 1996 Nov [cited 2020 Apr 6];3(4):261-7. Available from: http://www.ncbi.nlm.nih.gov/pubmed/12741960

36. Donnelly BJ, Saliken JC, Ernst DS, Ali-Ridha N, Brasher PMA, Robinson JW, et al. Prospective trial of cryosurgical ablation of the prostate: five-year results. Urology [Internet]. 2002 Oct [cited 2020 Apr 6];60(4):645-9. Available from: http://www.ncbi.nlm.nih.gov/pubmed/12385926

37. Saliken JC, Donnelly BJ, Ernst S, Rewcastle J, Wiseman D. Prostate cryotherapy: practicalities and applications from the Calgary experience. Can Assoc Radiol J [Internet]. 2001 Jun [cited 2020 Apr 6];52(3):165-73. Available from: http://www.ncbi.nlm.nih.gov/pubmed/11436411

38. Robinson JW, Donnelly BJ, Siever JE, Saliken JC, Ernst SD, Rewcastle JC, et al. A randomized trial of external beam radiotherapy versus cryoablation in patients with localized prostate cancer: Quality of life outcomes. Cancer. 2009 Oct 15;115(20):4695-704.

39. Robinson JW, Donnelly BJ, Coupland K, Siever JE, Saliken JC, Scott C, et al. Quality of life 2 years after salvage cryosurgery for the treatment of local recurrence of prostate cancer after radiotherapy. Urol Oncol Semin Orig Investig [Internet]. 2006 Nov [cited 2020 Apr 6];24(6):472-86. Available from: http://www.ncbi.nlm.nih.gov/pubmed/17138127

40. Robinson JW, Saliken JC, Donnelly BJ, Barnes P, Guyn L. Quality-of-life outcomes for men treated with cryosurgery for localized prostate carcinoma. Cancer. 1999 Nov 1;86(9):1793-801.

41. Baissalov R, Sandison GA, Donnelly BJ, Saliken JC, McKinnon JG, Muldrew K, et al. Suppression of high-density artefacts in X-ray CT images using temporal digital subtraction with application to cryotherapy. Phys Med Biol [Internet]. 2000 May [cited 2020 Apr 6];45(5):N53-59. Available from: http://www.ncbi.nlm.nih.gov/pubmed/10843116

42. Saliken JC, Donnelly BJ, Rewcastle JC. The evolution and state of modern technology for prostate cryosurgery. Urology [Internet]. 2002 Aug [cited 2020 Apr 6];60(2 Suppl 1):26-33. Available from: http://www.ncbi.nlm.nih.gov/pubmed/12206845

43. Sandison GA, Loye MP, Rewcastle JC, Hahn LJ, Saliken JC, McKinnon JG, et al. $\mathrm{X}$-ray CT monitoring of iceball growth and thermal distribution during cryosurgery. Phys Med Biol [Internet]. 1998 Nov [cited 2020 Apr

6];43(11):3309-24. Available from: 
http://www.ncbi.nlm.nih.gov/pubmed/9832018

44. Muldrew K, Rewcastle J, Donnelly BJ, Saliken JC, Liang S, Goldie S, et al.

Flounder antifreeze peptides increase the efficacy of cryosurgery. Cryobiology [Internet]. 2001 May [cited 2020 Apr 6];42(3):182-9. Available from: http://www.ncbi.nlm.nih.gov/pubmed/11578117

45. Babaian RJ, Donnelly B, Bahn D, Baust JG, Dineen M, Ellis D, et al. Best Practice Statement on Cryosurgery for the Treatment of Localized Prostate Cancer. Vol. 180, Journal of Urology. 2008. p. 1993-2004.

46. Donnelly BJ, Saliken JC, Ernst DS, Weber B, Robinson JW, Brasher PMA, et al. Role of transrectal ultrasound guided salvage cryosurgery for recurrent prostate carcinoma after radiotherapy. Prostate Cancer Prostatic Dis [Internet]. 2005 [cited 2019 Oct 28];8(3):235-42. Available from: http://www.ncbi.nlm.nih.gov/pubmed/15983627

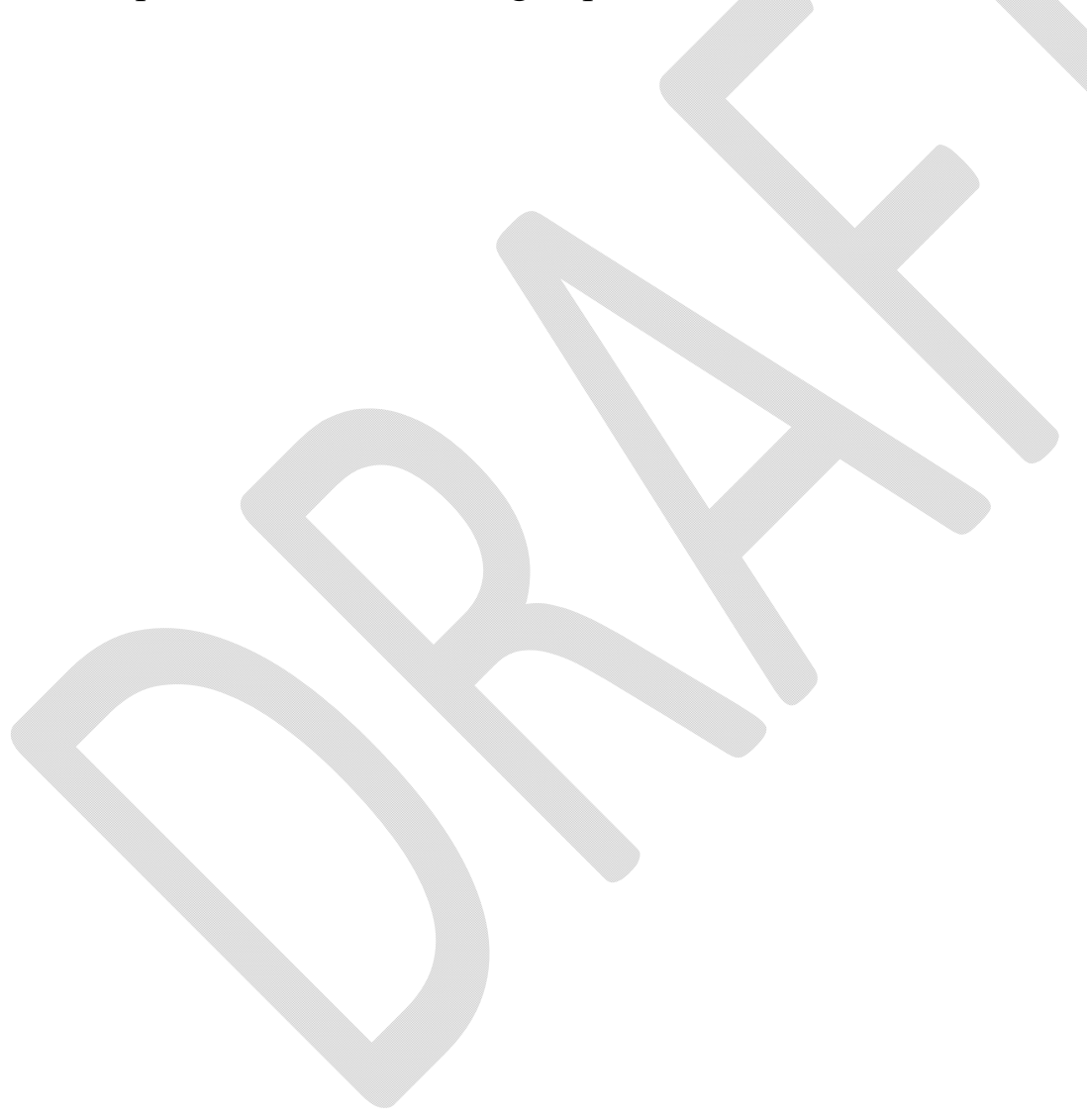




\section{Figures and Tables}

Fig. 1. Three-dimensional ultrasound (US) imaging system. (A) Schematic design of 3D US and reconstruction. (B) Transrectal US image of prostate sagittal and transverse views with cryoprobes inserted. (C) Coronal view showing insertion - correct placement (white arrow) for proper gland coverage - "flared" instead of parallel direction. (D) 3D view showing expanding ice ball (dark sphere) nearing rectal wall.

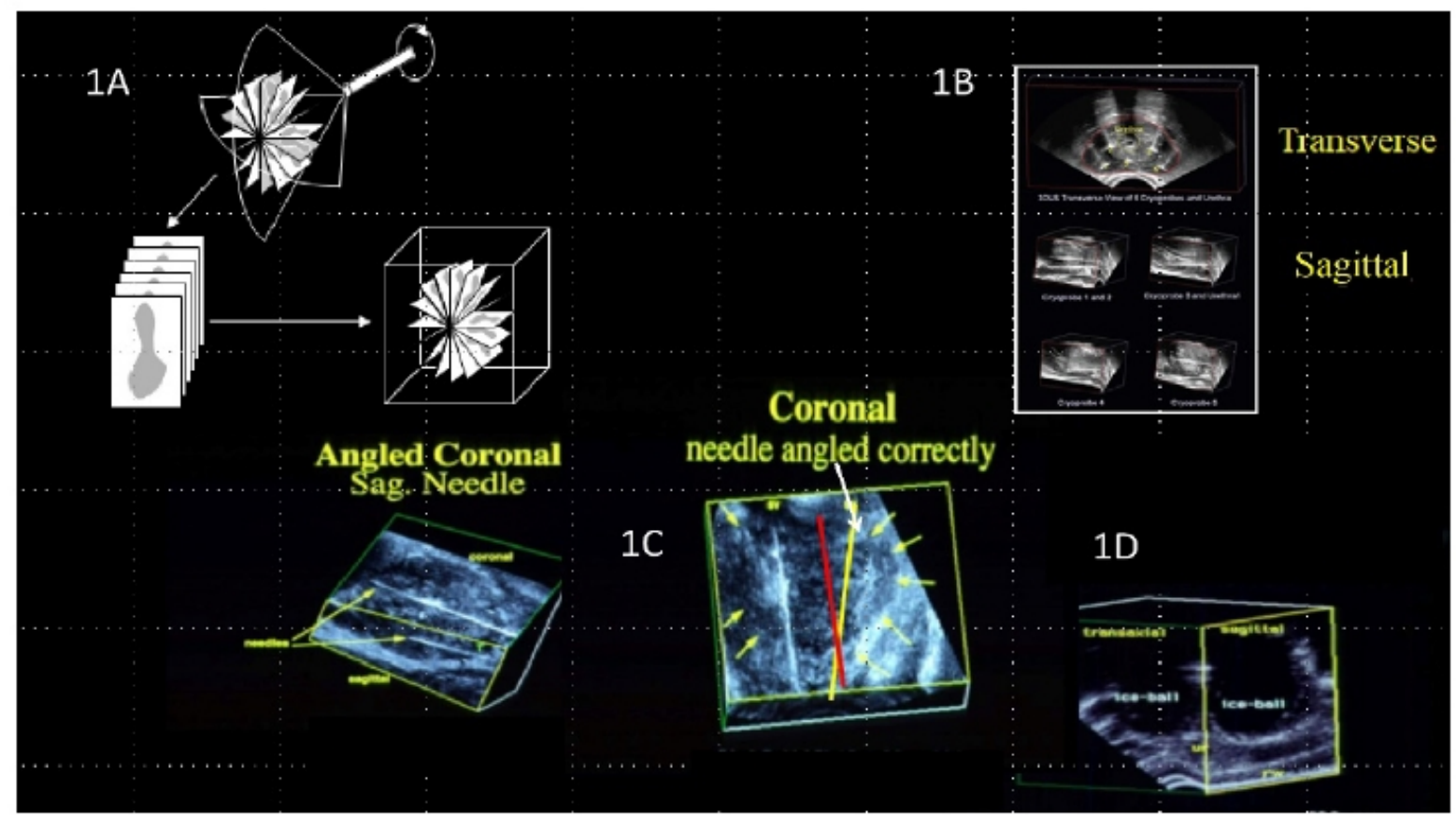

